CZASOPISMO INŻYNIERII LA¿OWEJ, ŚRODOWISKA I ARCHITEKTURY JOURNAL OF CIVIL ENGINEERING, ENVIRONMENT AND ARCHITECTURE

JCEEA, t. XXXIII, z. 63 (3/16), lipiec-wrzesień 2016, s. 365-372

\author{
Estera PRZENZAK ${ }^{1}$ \\ Justyna TARNOWSKA ${ }^{2}$ \\ Mariusz FILIPOWICZ ${ }^{3}$
}

\title{
SYMULACJE ODBIORNIKA CIEPLA WYSOKOTEMPERATUROWEGO PRACUJĄCEGO W UKŁADZIE HELIOENERGETYCZNYM
}

\begin{abstract}
W niniejszym artykule przedstawione zostały wyniki symulacji komputerowych układu absorpcji skoncentrowanego promieniowania słonecznego przez odbiornik ciepła wysokotemperaturowego. Przedstawiono metodę Śledzenia Promienia opartą na algorytmie Monte Carlo (Ray Tracing Monte Carlo - RTMC).

Przeanalizowany został układ dwuelementowego koncentratora promieniowania słonecznego i różnych wersji odbiornika ciepła wysokotemperaturowego. Zaproponowano odbiorniki: płaski, wypukły oraz wklęsły. Przy tym dwa ostatnie przeanalizowano w wersjach z różnymi promieniami ich krzywizny tj. dla promienia 40, $60 \mathrm{oraz} 90 \mathrm{~cm}$. Symulacje przebiegu promieni w układzie optycznym koncentratora przeprowadzono dla odbiorników umiejscowionych w różnych odległościach od powierzchni lustra skupiającego.

W efekcie przeprowadzonych badań wygenerowano znormalizowane mapy rozkładu natężenia promieniowania na powierzchniach absorpcyjnych odbiorników oraz obliczono wzmocnienie promieniowania na analizowanych powierzchniach. $\mathrm{Na}$ ich podstawie wskazano najkorzystniejsze wersje odbiornika $\mathrm{z}$ optymalnym umiejscowieniem względem koncentratora.

Wykazano, że pomimo osiągnięcia najwyższego wzmocnienia przez odbiornik wypukły, najlepszym rozwiązaniem będzie zastosowanie odbiornika płaskiego. Jest to spowodowane przede wszystkim bardzo niekorzystnym rozkładem natężenia na powierzchni odbiornika wypukłego oraz zbyt małym wzrostem wzmocnienia promieniowania względem odbiornika płaskiego. Zaznaczono, że dodatkową zaletą odbiornika płaskiego jest jego prostota konstrukcji.
\end{abstract}

Słowa kluczowe: Ray Tracing, Monte Carlo, symulacje komputerowe, skoncentrowane promieniowanie słoneczne, absorpcja promieniowania słonecznego

\footnotetext{
${ }^{1}$ Autor do korespondencji / corresponding author: Estera Przenzak, AGH Akademia Górniczo-Hutnicza, Wydział Energetyki i Paliw, al. Mickiewicza 30, 30-059 Kraków; tel. 126173428; esterap@agh.edu.pl

2 Justyna Tarnowska, AGH Akademia Górniczo-Hutnicza, Wydział Energetyki i Paliw, al. Mickiewicza 30, 30-059 Kraków; tarnowska.justynna@gmail.com

${ }^{3}$ Mariusz Filipowicz, AGH Akademia Górniczo-Hutnicza, Wydział Energetyki i Paliw, al. Mickiewicza 30, 30-059 Kraków; tel. 126175192; filipow@agh.edu.pl
} 


\section{Wprowadzenie}

Energia promieniowania słonecznego jest coraz częściej wykorzystywana. Zaspokojenie potrzeb związanych z ogrzaniem wody użytkowej czy centralnego ogrzewania nie stanowi już wyzwania. Obecnie na całym świecie badane i projektowane są instalacje słoneczne umożliwiające m.in. produkcję chłodu, generację energii mechanicznej czy zgazowanie paliw stałych. Jest to możliwe głównie dzięki zastosowaniu koncentratorów promieniowania słonecznego [1-4]. Realizacja badań eksperymentalnych nad układami skupiającymi promieniowanie słoneczne jest jednak dość trudna. Wynika to z faktu, iż promieniowanie słoneczne jest niewidoczne, a w ognisku skupionych promieni panują wysokie temperatury. W kwestii efektywności, istotną rolę odgrywają układy absorberów skoncentrowanego promieniowania tj. odbiorniki ciepła wysokotemperaturowego. Wyznaczenie optymalnych warunków pracy takich układów ich badanie i pomiary są często bardzo trudne lub czasem niemożliwe do zrealizowania. Ułatwieniem są tutaj symulacje komputerowe [5-7].

\section{Opis procedury badawczej}

\subsection{Metoda Śledzenia Promienia typu Monte Carlo}

W celu przeprowadzenia badań nad systemami helioenergetycznymi stosuje się często zmodyfikowaną algorytmem Monte Carlo metodę Sledzenia Promieni (RTMC). Standardowa metoda Sledzenia Promienia wykorzystywana jest do generowania realistycznych obrazów graficznych. W metodzie tej śledzone są tylko te promienie, które przechodząc przez scenę optyczną trafiają do oka obserwatora (kamery). Zmodyfikowana metoda zaś polega na śledzeniu wszystkich promieni generowanych przez źródło światła. Dzięki algorytmowi Monte Carlo promienie emitowane są losowo z różnych punktów powierzchni źródła światła oraz w różnych kierunkach. RTMC wykorzystuje techniki redukcji wariancji w celu zmniejszenia liczby promieni koniecznych do wyemitowania. Czas obliczeń jest zatem dość krótki. Wyniki analiz systemów helioenergetycznych poprzez symulacjekomputerowe oparte na metodzie RTMC opisane zostały m.in. w [1-4, 8].

\subsection{Charakterystyka analizowanego systemu helioenergetycznego}

Oprogramowanie do symulacji propagacji promieni wykorzystane zostało do wykonania wstępnej optymalizacji hybrydowego systemu kolektorów słonecznych z koncentratorem promieniowania słonecznego. Wysokotemperaturowe ciepło generowane za pomocą analizowanej instalacji ma służyć do produkcji chłodu oraz zasilenia wody użytkowej. System zasilany jest w pełni energią promieniowania słonecznego.

Czynnik roboczy (olej termiczny) ogrzewany jest wstępnie w dwóch płaskich kolektorach słonecznych. Wysoką temperaturę generuje się natomiast za 
pomocą koncentratora promieniowania słonecznego (rys.1). Jest to paraboliczna czasza o średnicy $1.8 \mathrm{~m}$ pokryta folią refleksyjną. W centralnej jej części umieszczono paraboliczne lustro o grubości ścianki $4 \mathrm{~mm}$ i średnicy $1.2 \mathrm{~m}$. $\mathrm{W}$ analizowanym systemie helioenergetycznym występują dwa ogniska skupienia promieni: w odległości $70 \mathrm{~cm}$ oraz $85 \mathrm{~cm}$ od powierzchni lustra. Koncentrator wyposażony został w układ śledzenia położenia Słońca oparty na czujniku różnicowym. Instalacja zamontowana została na dachu Katedry Zrównoważonego Rozwoju Energetycznego, AGH w Krakowie. Wysokotemperaturowe ciepło ma służyć do zasilenia chłodziarki absorpcyjnej.

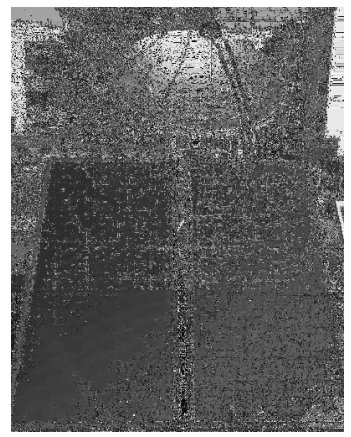

Rys. 1. Widok kolektorów słonecznych Rys. 2. Dodatkowe wyposażenie instai koncentratora promieniowania słonecznego lacji w laboratorium

Fig. 1. The view of solar radiation concen- Fig. 2. Additional equipment in the trator and solar panels installation

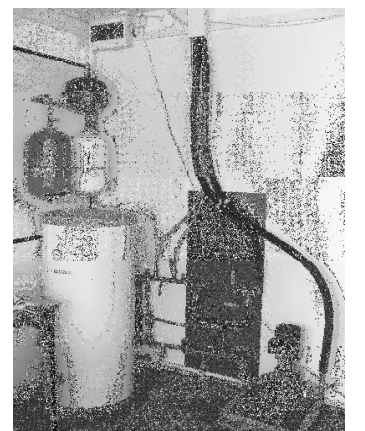

laboratory

Armatura i pozostałe urządzenia instalacji zamontowane zostały w laboratorium (rys.2). Wymuszenie przepływu medium roboczego następuje za pomocą pompy obiegowej o mocy $370 \mathrm{~W}$. Obecnie, generowane ciepło wykorzystywane jest do zasilania zbiornika buforowego wody użytkowej. Instalacja dodatkowo wyposażona została $\mathrm{w}$ naczynie przeponowe $\mathrm{z}$ układem przedwstępnego chłodzenia, a także w chłodnicę wentylatorową wykorzystywaną w przypadku osiągnięcia zbyt wysokich temperatur (zabezpieczenie instalacji w trakcie trwania całodniowych badań). System wyposażony został również w automatykę kontrolno-pomiarową opartą na sterowniku programowalnym (PLC). Do sterownika podpiętych jest szereg elementów pomiarowych takich jak: czujniki temperatury, ciśnienia, natężenia promieniowania słonecznego, przepływomierz. Układ automatyki pozwala również na sterowanie wydajnością pompy obiegowej (za pomoca falownika) oraz chłodni wentylatorowej.

Ważnym elementem instalacji pod kątem generacji wysokotemperaturowego ciepła jest odbiornik umieszczany $\mathrm{w}$ ognisku skupionego promieniowania słonecznego. Na efektywność absorpcji promieniowania ma wpływ przede wszystkim kształt oraz umiejscowienie odbiornika w układzie geometrycznym koncentratora. Z kolei efektywność odbioru ciepła wysokotemperaturowego przez medium robocze zależna jest od geometrii wewnętrznej odbiornika. 


\section{Metodyka i wyniki badań}

W celu optymalizacji procesu absorpcji skoncentrowanego promieniowania słonecznego zaproponowano różne geometrie zewnętrzne odbiornika wysokotemperaturowego ciepła. Następnie wykorzystano metodę Śledzenia Promienia do wykonania symulacji analizowanych odbiorników pracujących w różnym umiejscowieniu układu koncentratora. Mianowicie, zmieniano odległość odbiornika od środka powierzchni lustra parabolicznego (odległość L).

Na rysunku 3 przedstawiono geometrię odbiorników płaskiego, wypukłego oraz wklęsłego. Każdy z nich ma średnicę $18 \mathrm{~cm}$. Wersje wypukła oraz wklęsła wykonane zostały w trzech wariantach każda, różniących się promieniem krzywizny: 40, 60 i 90cm (oznaczenia odpowiednio R40, R60, R90). Odbiorniki płaski oraz wypukły R60, zostały zrealizowane w rzeczywistości (rys.4) i prowadzone są badania eksperymentalne opisane m.in. w [5-7]. Odbiorniki ciepła wysokotemperaturowego wykonane zostały $\mathrm{z}$ aluminium $\mathrm{z}$ wyfrezowanym wewnątrz kanałem przez który przepływa olej termiczny. Powierzchnia absorpcyjna pokryta została czarną farbą.

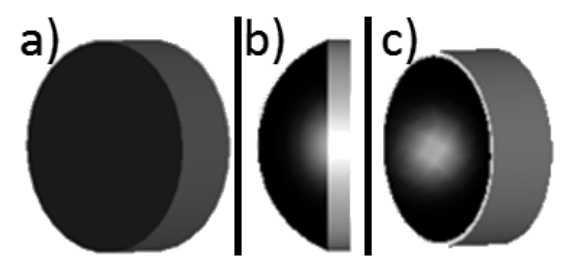

Rys. 3. Geometria odbiorników: a) płaskiego, b) wypukłego oraz c) wklęsłego

Fig. 3. Geometry of heat receivers: a) flat, b) convex and c) concave
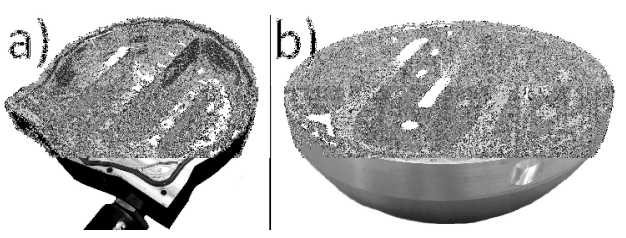

Rys. 4. Widok geometrii wewnętrznej rzeczywistych odbiorników: a) płaskiego, b) wypukłego

Fig. 4. The view of inside geometry of real heat receivers: a) flat, b) convex

Symulacje komputerowe wykonano przy pomocy oprogramowania TracePro firmy Lambda Research [9]. Program pozwala na import geometrii w standardowych dla techniki CAD rozszerzeniach (m.in. *.SAT). TracePro posiada bogaty zasób danych zawierających informacje o właściwościach różnorodnych materiałów oraz powierzchni. Użytkownik ma również możliwość ich edytowania oraz wprowadzania własnych. Główne właściwości wykorzystywane na potrzeby omawianego układu helioenergetyczne wymieniono poniżej:

- powierzchnie refleksyjne (lustro i czasza): współczynnik refleksyjności 0.95, - powierzchnie absorpcyjne (czarna farba): współczynnik absorpcji 0.9,

- źródło światła (Słońce): Spektrum promieniowania słonecznego zgodne ze standardem: ASTM E-490-00 [10].

W wyniku przeprowadzonych analiz, na podstawie wyników symulacji obliczono wzmocnienie promieniowania na powierzchni absorpcyjnej omawianych odbiorników ciepła (rys. 5). 


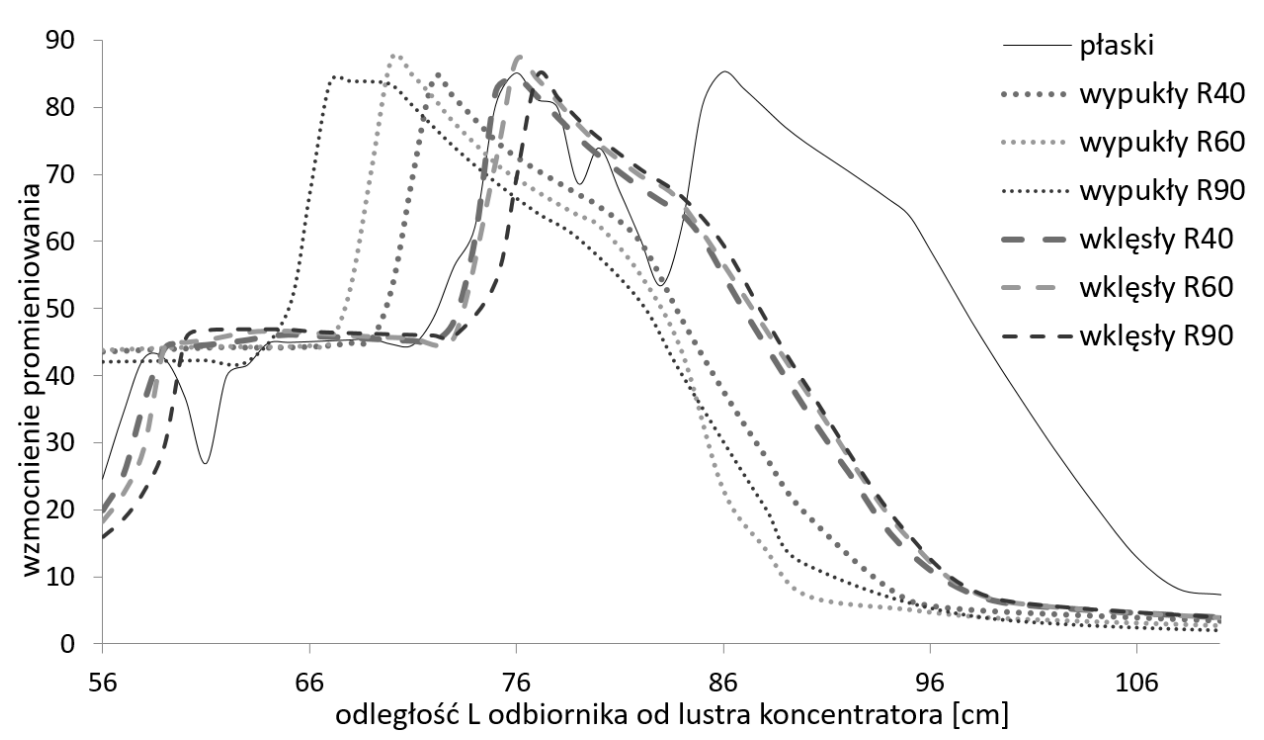

Rys. 5. Wzmocnienie promieniowania na powierzchni różnych rodzajów odbiorników wysokotemperaturowego ciepła w zależności od ich umiejscowienia

Fig. 5. The radiation reinforcement on high temperature heat receivers placed in different distances from focusing mirror

Na wykresie wzmocnienia (rys.5) zaobserwować można, że każdy odbiornik posiada zazwyczaj jedno optymalne umiejscowienie w układzie koncentratora. Wyjątkiem jest odbiornik płaski dla którego zarówno odległość L równa 76 jak i $86 \mathrm{~cm}$ jest efektywna. Z kolei zaletą odbiornika wypukłego R90 jest to, że w odległościach $67-70 \mathrm{~cm}$ wzmocnienie jest stałe. Najwyższą wartość równą ok. 90 osiąga odbiornik wypukły R60.

Oprogramowanie TracePro pozwala również na generację map rozkładu natężenia promieniowania na wybranych powierzchniach analizowanego układu optycznego (rys.6). Na potrzeby omawianych badań przeanalizowano mapy znormalizowanej mocy promieniowania emitowanego przez źródło-Słońce dla powierzchni absorpcyjnej odbiornika. Moc znormalizowana wynosiła $1 \mathrm{~W}$, natomiast nieznormalizowana około $2980 \mathrm{~W}$ (średnica źródła światła wynosi $1.95 \mathrm{~m}$ co daje powierzchnię $2.98 \mathrm{~m}^{2}$, przy natężeniu promieniowania słonecznego $1000 \mathrm{~W} / \mathrm{m}^{2}$ ).

Mapy z oznaczeniem a) oraz d) -i) przedstawiają rozkład natężenia dla odbiorników charakteryzujących się najwyższym wzmocnieniem promieniowania na ich powierzchniach. Widoczne jest, że najkorzystniejszy rozkład natężenia promieniowania osiąga się $\mathrm{w}$ przypadku odbiornika płaskiego. Najgorzej pod tym kątem prezentuje się odbiornik wypukły. Dla każdej z krzywizn odbiornik ten charakteryzuje się bardzo nierównomiernym rozkładem natężenia promieniowania na powierzchni absorpcyjnej. Promienie skupiają się na niewielkim obszarze w centralnej części odbiornika $\left(\mathrm{ok} 0,5 \mathrm{~cm}^{2}\right)$ oraz w mniejszym stopniu na powierzchni $w$ kształcie pierścienia po zewnętrznej części absorbera. Z kolei 
wyniki dla odbiornika wklęsłego są dość zróżnicowane. Najlepszy rozkład obserwuje się w przypadku krzywizn R40 oraz R90, najgorszy natomiast w przypadku R60.

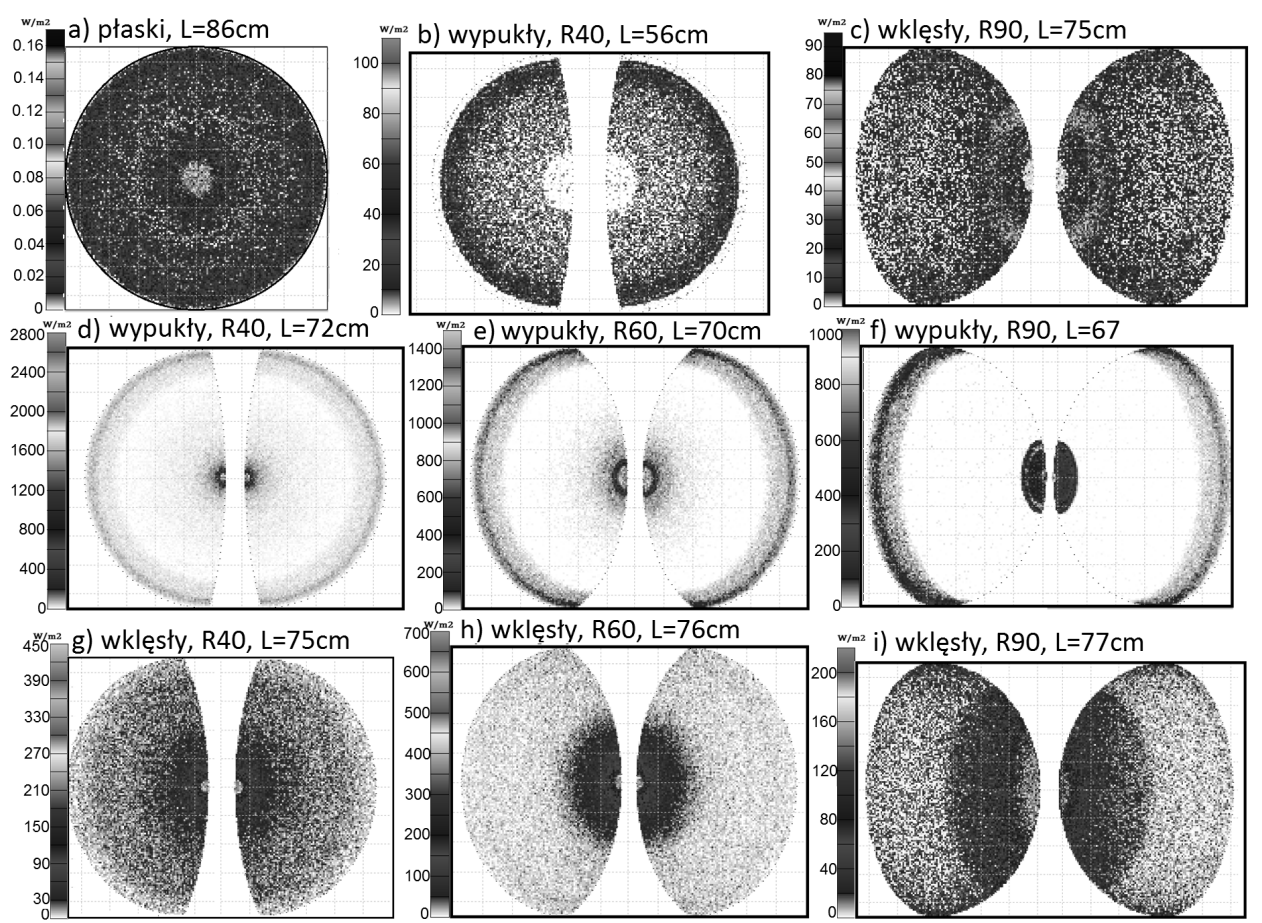

Rys. 6. Znormalizowane mapy rozkładu natężenia promieniowania na powierzchni absorpcyjnej odbiornika

Fig. 6. Normalized maps of flux distribution on receiver absorption surface

Widoczne jest, że mapy dla odbiorników wklęsłego i wypukłego (dla odległości najwyższego wzmocnienia) nie przedstawiają wystarczająco dobrego rozkładu natężenia. Symulacje pokazują jednak, że istnieje takie umiejscowienie dla obu odbiorników, które jest korzystne pod kątem rozkładu natężenia promieniowania na absorberze (rys. 6 mapy b oraz c). Umiejscowienia te nie są jednak tak dobre jak wyniki uzyskane dla odbiornika płaskiego. Ponadto, wzmocnienie promieniowania jest dużo niższe niż dla map d-i. Mianowicie, wybranie najkorzystniejszego rozkładu promieniowania w przypadku odbiornika wklęsłego wiąże się ze spadkiem wzmocnienia prawie o $40 \%$ (w odniesieniu do odbiornika wklęsłego o najwyższym wzmocnieniu), natomiast w przypadku odbiornika wypukłego o połowę.

Biorąc pod uwagę mapy rozkładu natężenia promieniowania na powierzchni absorpcyjnej odbiornika, strumień zaabsorbowanej energii oraz stopień komplikacji odbiornika najlepszym rozwiązaniem wydaje się być właśnie odbiornik płaski. Jednak konieczne jest przeprowadzenie dodatkowych badań eksperymen- 
talnych oraz symulacji dotyczących przekazu ciepła do medium roboczego. Pozwoli to określić również wpływ wiatru (straty ciepła przez konwekcję) oraz straty ciepła na drodze promieniowania. W kolejnych badaniach rozważyć należy możliwość zastosowania izolacji termicznej składającej się z warstwy zabezpieczającej tylną część oraz boki odbiornika, a także sensowność osłonięcia absorbera przeźroczystą izolacją cieplną.

\section{Wnioski}

Koncentratory promieniowania słonecznego stają się powoli alternatywą dla klasycznych instalacji z kolektorami słonecznymi. Dają one bowiem szersze możliwości wykorzystania energii promieniowania słonecznego. Ważnym jednak elementem w optymalizacji takich układów jest odbiornik ciepła wysokotemperaturowego. Prowadzenie badań eksperymentalnych jest konieczne, ale wiąże się często $\mathrm{z}$ wysokimi kosztami wyprodukowania prototypów oraz długim czasem realizacji. Dlatego najlepszym rozwiązaniem jest posiłkowanie się symulacjami komputerowymi już na etapie projektowania.

Analizując mapy dla przedstawionych geometrii odbiornika ciepła wysokotemperaturowego, najrozsądniejszym wydaje się wskazanie odbiorników płaskiego $(\mathrm{L}=86 \mathrm{~cm})$ oraz wklęsłego $(\mathrm{R} 90, \mathrm{~L}=77 \mathrm{~cm})$ jako wariantów najlepszych. Absorber wypukły, przy którym zanotowano najwyższy strumień zaabsorbowanego promieniowania tj. $2 \mathrm{~kW}(\mathrm{R} 60, \mathrm{~L}=70)$ będzie stanowił problem nie tylko pod kątem materiałowym (niekorzystny rozkład natężenia promieniowania), ale również pod kątem zabezpieczenia przed stratami ciepła. Najkorzystniejsze wzmocnienie dla odbiorników płaskiego i wklęsłego jest jedynie o 1-3\% mniejsze od odbiornika wypukłego, przy czym to odbiornik płaski charakteryzuje się lepszym rozkładem natężenia promieniowania słonecznego i prostotą konstrukcji.

Praca wykonana $w$ ramach działalności statutowej WEiP, AGH

„Badania uwarunkowań zrównoważonego rozwoju energetycznego”

\section{Literatura}

[1] Leon N., Aguayo H., Garcia H., Anaya A.: Computer aided optimization/innovation of passive tracking solar concentration Fresnel lens, IFIP AICT no 355, 2011, pp. 57-70.

[2] Bader R., Haueter P., Pedretti A., Steinfeld A.: Optical design of a novel 2-stage solar through concentrator based on pneumatic polymeric structures, Jornal of Solar Energy Engineering no 131, 2009, pp. 031007-1/9.

[3] Pujol-Nadal R., Martinez-Moll V., Sallaberry F., Moia-Pol A.: Optical and thermal characterization of a variable geometry concentrator using ray-tracing tools and experimental data, Applied Energy, no 155, 2015, pp. 110-119.

[4] Rodriguez-Sanchez D., Rosengarten G.: Improving the concentration ratio of parabolic troughs using a second-stage flat mirror, Applied Energy, no 159, 2015, pp. 620-632. 
[5] Przenzak E., Filipowicz M.: Hybrid solar receiver as a source of high-temperature medium for an absorption chiller supply, Experimental Fluid Mechanics, 2015, pp. 656-663.

[6] Bożek E., Zdunek M.: Nowoczesne systemy chłodnicze zasilane skoncentrowanym promieniowaniem słonecznym, Bezpieczeństwo energetyczne - rynki surowców i energii: energetyka w czasach politycznej niestabilności, 2015, s. 687-694.

[7] Bożek E., Szubel M.: The numerical model of the high temperature receiver of the concentrated solar radiation, SDEWES 2015, Conference on Sustainable Development of Energy, Water and Environment Systems, Dubrownik, (2015), pp.1-12.

[8] Kim Y., Han G. Y., Seo T.: An evaluation on thermal performance of CPC solar collector, International Communications in Heat and Mass Transfer 35, 2008, pp. 446-457.

[9] TracePro software, Lambda Research Corporation, www.lambdaresearch.com, last access 12.06.2016.

[10] Allen C. W., Astrophysical Quantities, The Athlone Press, London, 1963.

\section{SIMULATIONS OF HIGH-TEMPERATURE HEAT RECEIVER IN HELIOENERGETIC SYSTEM}

\section{S u m m a r y}

This article presents the results of computer simulations of high-temperature heat receiver powered by concentrated solar radiation. Ray Tracing Monte Carlo (RTMC) methodology was presented.

Installation uses two optical elements with different versions of high-temperature heat receiver was analyzed. Flat, convex and concave geometry of the concentrated radiation absorber were proposed. Convex, and concave receivers were analyzed in three more variants - with different radius curvature ie. 40,60 and $90 \mathrm{~cm}$. In addition, the Ray Tracing simulations was performed for varied distances of heat receivers from the focusing mirror.

As the results of computer simulations, normalized maps of flux distribution on the absorbing surfaces of the heat receivers were generated. The best versions of the receivers with the optimal location of them were indicated. Not only the flux distribution but also the radiation gain were taken into consideration.

It has been shown that, despite the highest gain on the convex heat receiver, the flat one is the best solution. This is primarily caused by very disadvantageous flux distribution on convex receiver and insignificant difference in radiation gain in both cases. Also the simplicity the flat heat receiver was emphasized.

Keywords: Ray Tracing, Monte Carlo, computer simulations, concentrated solar radiation, solar radiation absorpcion

DOI: $10.7862 / \mathrm{rb} .2016 .219$

Przestano do redakcji: $13.06 .2016 r$.

Przyjęto do druku: 30.11 .2016 r. 